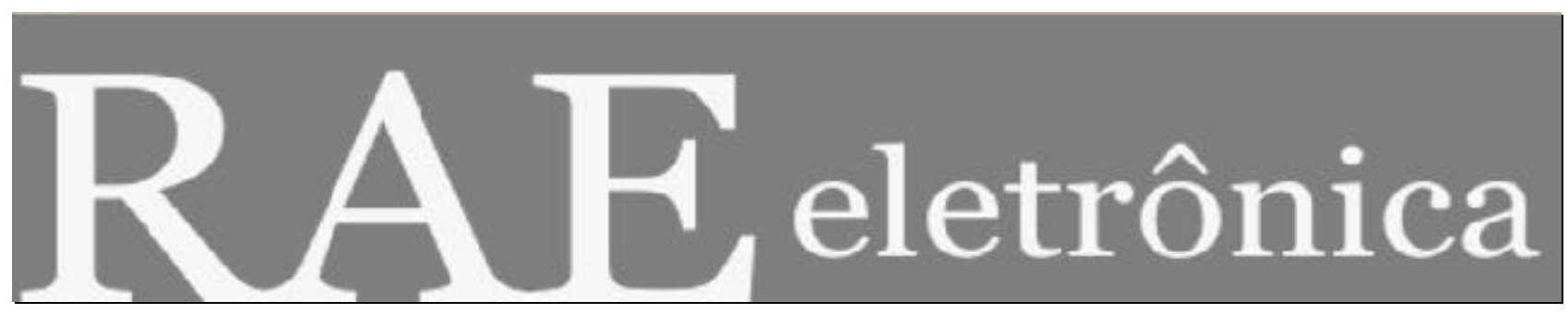

\title{
FÓRUM ESTUDOS CRÍTICOS EM ADMINISTRAÇÃO
}

\section{APRESENTAÇÃO}

Por:

\section{Ana Paula Paes de Paula \\ Rafael Alcadipani}

RAE-eletrônica, v. 3, n. 2, Art. 24, jul./dez. 2004

http://www.rae.com.br/eletronica/index.cfm?FuseAction=Artigo \&ID=2375\&Secao=FOR.ESTCRI\&V olume $=3 \&$ Numero $=2 \& A n o=2004$

CCCopyright, 2004, RAE-eletrônica. Todos os direitos, inclusive de tradução, são reservados. É permitido citar parte de artigos sem autorização prévia desde que seja identificada a fonte. A reprodução total de artigos é proibida. Os artigos só devem ser usados para uso pessoal e nãocomercial. Em caso de dúvidas, consulte a redação: redacao@ rae.com.br.

A RAE-eletrônica é a revista on-line da FGV-EAESP, totalmente aberta e criada com o objetivo de agilizar a veiculação de trabalhos inéditos. Lançada em janeiro de 2002, com perfil acadêmico, é dedicada a professores, pesquisadores e estudantes. Para mais informações consulte o site www.rae.com.br/eletronica.

\section{RAE-eletrônica}

ISSN 1676-5648

(C2004 Fundação Getulio Vargas - Escola de Administração de Empresas de São Paulo.

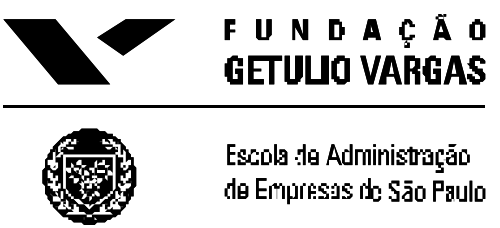




\section{FÓRUM ESTUDOS CRÍTICOS EM ADMINISTRAÇÃO}

A idéia de realizar este fórum surgiu da necessidade de verificar o perfil dos estudos organizacionais críticos no Brasil. Nas últimas décadas, as transformações tecnológicas, sociais e políticas trouxeram consigo um crescente questionamento da influência das atividades do management na vida humana. A preocupação com o seu caráter instrumental e ideológico institucionalizou um movimento chamado Critical Management Studies que se consolidou após a publicação do livro de Alvesson e Willmott (1992).

Durante a década de 1990, este movimento se espraiou pela Europa e Estados Unidos. Atualmente, a Universidade de Lancaster oferece doutoramento sobre o tema, vários números especiais de periódicos foram realizados sobre o assunto (Administrative Science Quarterly, 1998; Organization, 2002), a IV Critical Management Studies Conference será realizada no próximo ano na Universidade de Cambridge e desde o ano passado a Academy of Management possui uma divisão, que é uma das que mais possui filiados, sobre o assunto.

No Brasil, o tema começou a ser mais discutido a partir da publicação da edição brasileira do Handbook of Organizational Studies (CLEGG, S.; HARDY, C. CALDAS, M.; FACHIN, R. e FISCHER, T., 1999), pois este trazia uma tradução do artigo de Critical Theory and Postmodernism Approaches to Organizational Studies de Alvesson e Deetz (1996) acompanhado de uma nota técnica. $\mathrm{O}$ texto talvez tenha chamado atenção de alguns acadêmicos brasileiros para aportes teóricos como a teoria crítica e o pós-estruturalismo, mas observando a produção em estudos organizacionais no Brasil é possível notar que artigos escritos em uma perspectiva crítica antecedem o movimento europeu e estadunidense.

Nos círculos acadêmicos, Fernando C. Prestes Motta nos chamava atenção para o pioneirismo de Alberto Guerreiro Ramos e Maurício Tragtenberg, cujos trabalhos carregam uma forte identidade crítica, questionando a teoria organizacional convencional e o status quo. Por outro lado, sua própria obra forneceu mais fôlego para a solidificação desta perspectiva na análise organizacional brasileira.

Guerreiro Ramos dedica sua obra à edificação de uma sociologia crítica das organizações e de uma visão humanista, abordando uma nova maneira de se pensar a teoria organizacional em A nova ciência das organizações (Guerreiro Ramos, 1981). Maurício não poupa suas críticas às tentativas de cooptação do trabalhador através da ideologia gerencial (Tragtenberg, 1979), mas também se volta para o estudo da educação como vetor de transformação social. Fernando C. Prestes Motta consolida a teoria das organizações no Brasil, realizando um percur so entre a crítica da racionalização burocrática e a centralidade do indivíduo nas organizações, sugerindo que a mudança está associada ao entendimento da psique individual e coletiva.

Percebendo a crescente importância desta perspectiva no cenário acadêmico nacional e internacional, a RAE convidou o professor Fernando C. Prestes Motta e os dois autores desta introdução para organizar um fórum especial sobre Estudos Organizacionais Críticos. Infelizmente Fernando C. Prestes Motta nos deixou antes de finalizarmos nossa jornada. No entanto, decidimos continuar este trabalho e dedicá-lo a sua memória.

Nosso mestre foi um dos principais acadêmicos em estudos organizacionais no Brasil e é um dos poucos cujos trabalhos possuem uma lógica intrínseca que caracterizam uma obra no verdadeiro sentido do termo. O seu trabalho "Teoria Geral da Administração" (Prestes Motta, 2001) foi, e ainda é, 
referência para o ensino, bem como seus inúmeros livros, artigos e relatórios de pesquisa. Fernando foi um ser humano notável, responsável pela formação de muitos dos pesquisadores hoje em atividade no nosso país e deixou muitas saudades. Prestamos assim a ele mais esta home nagem.

O percurso para a construção deste fórum foi pontuado de dificuldades. A primeira delas foi a definição do que seria um artigo crítico. Para Alvesson e Willmott $(1992,1996)$ e Fournier e Grey (2000), os estudos críticos em organização são caracterizados por três aspectos fundamentais: visão desnaturalizada da administração, intenções desvinculadas de esempenho e busca de emancipação. Consultando a rede de pesquisadores brasileiros interessada no assunto, percebemos uma concordância em relação a maior parte destes pontos, mas alguma controvérsia em torno da intenção não performática, que é coerente com o posicionamento politizado dos pioneiros dos estudos críticos no Brasil. Assim, a lguns colocam em questão se uma posição mais ativa em termos de recomendações por parte dos pesquisadores críticos não seria consistente com sua busca de transformação social.

Em novo livro, o inglês Martin Parker (2002) examina o movimento de estudos críticos europeu, enfatizando principalmente aqueles realizados no Reino Unido. Em sua análise, ele faz uma crítica justamente do caráter elitista que estes estudos vêm assumindo na medida em que se restringem às fronteiras e acadêmicas e têm pouco impacto junto às organizações. Ao contra-senso apontado por Burrell e Morgan (1979) de que a grande maioria dos teóricos organizacionais faz parte de escolas de administração e de negócios sem apresentar respostas aos desafios práticos do cotidiano organizacional, Parker opõe a necessidade de qualificar estes estudos como parte da sociologia das organizações.

Parker então questiona porque os problemas organizacionais têm interessado tão pouco aos sociólogos e critica a tendência do critical management studies de valorizar muito pouco a literatura em sociologia das organizações que precede o "esclarecimento" de Alvesson e Willmott em 1992. Muito embora já esteja presente desde os anos 40 na sociologia das organizações no contexto internacional (Burnham, 1945; Bendix, 1956; Mills, 1956), como vimos, foi somente nos anos noventa que os estudos críticos ganharam proeminência.

Para Parker o critical management studies hoje representa uma forma muito particular de crítica pósestruturalista que exclui formas mais ortodoxas e bem estabelecidas de escrita anti-capitalista praticada pelos neo-marxistas. No Reino Unido ele representa uma tensão entre Marx e Foucault, entre realismo crítico e relativismo epistemológico, mas nos Estados Unidos, Escandinávia e Austrália as histórias e os significados são sem dúvida um tanto diferentes.

Este questionamento de Parker nos abre espaço para pensarmos o caso brasileiro. Como se caracterizam os estudos organizacionais críticos no Brasil? Podemos considerar realmente que eles apresentam uma abordagem distinta do mainstream europeu? Os 32 artigos que recebemos com a chamada realizada na RAE demonstraram que há uma grande heterogeneidade de temáticas e perspectivas teóricas, mas de uma maneira geral foi possível perceber que há uma certa fidelidade às suas raízes teóricas, como o marxismo e os teóricos da Escola de Frankfurt, tal como Davel e Alcadipani (2003) constataram em seu estudo preliminar. Há textos alinhados com os desenvolvimentos teóricos mais recentes, como o pós-estruturalismo, e outros em que há uma há uma clara intenção de autonomia em relação às proposições da corrente hegemônica européia.

Por outro lado, apesar das críticas serem em geral dissociadas de respostas práticas, parte delas defendem uma postura mais propositiva do ponto de vista político, que é consistente com os desenvolvimentos teóricos realizados por Maurício Tragtenberg e Alberto Guerreiro Ramos. Conforme 
já demonstramos, estes autores negam a busca por desempenho e eficiência como objetivo fundamental dos estudos organizacionais, mas ao mesmo tempo defendem uma posição reativa que nos leva a imaginar formas de organização alternativas ao gerencialismo e rotas possíveis para a emancipação.

Após processo de blind review foram selecionados 4 artigos. De um modo geral, buscamos representar a heterogeneidade constatada, além de valorizar artigos que revelam uma identidade para os estudos organizacionais brasileiros. Do ponto de vista das temáticas, os textos selecionados cobrem assuntos que são típicos dos estudos organizacionais críticos: crítica da racionalização burocrática, controle, relações de gênero e responsabilidade social.

O texto "Participação como controle social: uma crítica das estruturas organizacionais flexíveis" de João Marcelo Crubellate realiza críticas das novas formas de controle exercitadas pelas organizações ditas pós-burocráticas e pós-modernas. Já o texto "Um estudo da produção acadêmica em administração estratégica no Brasil na terminologia de Habermas" de José Rodrigues Filho parte do referencial habermasiano para demonstrar a inexistência de abordagens críticas e o apego ao referencial importado na produção brasileira na área de estratégia.

Os textos "Uma análise da dinâmica do poder e das relações de gênero no espaço organizacional" de Monica Carvalho Alves Capelle, Marlene Catarina de Oliveira Lopes Melo, Maria José Menezes Brito e Mozar José de Brito e "Responsabilidade Social Corporativa: por uma boa causa!?" de Gianna Maria de Paula Soares se destacam por ocuparem os extremos de um debate interno dos estudos críticos. O primeiro se baseia predominantemente em uma abordagem pós-estruturalista e o segundo, é um texto eminentemente neo-marxista. Oferecem assim um contraste teórico que interessa aos estudiosos da área.

Convidamos então os leitores a explorarem e comentarem os textos apresentados. A idéia de realizar um fórum na RAE Eletrônica está relacionada com a possibilidade de uma maior interação com a comunidade acadêmica. Por este motivo, estamos promovendo uma iniciativa inédita: os leitores que quiserem fazer um comentário escrito sobre os textos lidos, podem enviá-lo por e-mail para os organizadores deste fórum, pois temos a intenção de avaliá-los e publicá-los neste mesmo espaço.

Com este fórum esperamos estar começando a esboçar um retrato dos estudos organizacionais críticos no Brasil, bem como apontando possibilidades para a identidade de nossos críticos e caminhos para futuras investigações. Queremos agradecer a todos que contribuíram para que este trabalho fosse possível, principalmente ao corpo de avaliadores e editores que nele estiveram engajados. Reconhecemos que se trata apenas de um começo e convidamos a todos os interessados a analisarem os trabalhos dos colegas, a enviarem seus comentários para os organizadores, a participarem do e-group criticaadm@yahoogrupos.com.br e a promoverem conosco outras iniciativas que incentivem o desenvolvimento desta linha de pesquisa.

\section{REFERÊNCIAS BIBLIOGRÁFICAS}

ADMINISTRATIVE SCIENCE QUARTELY. Critical perspectives on organizational control. v. 43, n. 2, June 1998.

ALVESSON, M.; DEETZ, S. Critical Theory and Postmodernism Approaches to Organizational 
Studies. In: ClEGG, S.; HARDY, C.; NORD, W. R. (eds.) Handbook of Organization Studies. London: Sage, 1996.

ALVESSON, M. e WILLMOTT, H. Critical Management Studies. London: Sage, 1992.

BENDIX, R. Work and authority in industry. New York: Harper \& Row, 1956.

BURHAM, J. The managerial revolution. London: Penguin, 1945.

BURREL, G.; MORGAN, G. Sociological paradigms anda organizational analysis of the sociology of corporate life. London: Heinemann, 1979.

CLEGG, S; HARDY, C.; CALDAS, M.; FACHIN, R.; FISCHER, T. (Eds.) Handbook de Estudos Organizacionais. São Paulo: Atlas, 1999.

DAVEL, E.; ALCADIPANI, R. Estudos Críticos em Administração: a produção científica brasileira nos anos 1990. Revista de Administração de Empresas, v. 43, n.4, p.72-85, out./dez. 2003.

FORNIER, V.; GREY, C. At the critical moment: conditions and prospects for critical management studies. Human Relations, v. 53, n.1, p.7-32, 2000.

GUERREIRO RAMOS, A. A nova ciência das organizações: uma nova ciência das organizações. Rio de Janeiro: Ed itora da Fundação Getúlio Vargas, 1981.

MILLS, C. The power elite. New York: Oxford University Press, 1956.

ORGANIZATION. Critical Management Studies. v.9, n.3, August 2002.

PRESTES MOTTA, F. C. Teoria Geral da Administração: uma introdução. São Paulo: Pioneira, 2001.

PARKER, M. Against Management. Cambridge: Polity Press, Blackwell Publishers, 2002.

TRAGTENBERG, T. Burocracia e ideologia. São Paulo: Editora Ática, 1974.

\section{Ana Paula Paes de Paula}

Pesquisadora e pós-doutoranda da FGV-EAESP/FAPESP. Professora do Programa de Mestrado em Administração da Universidade Paulista (UNIP).

E-mail: appaula@uol.com.br

\section{Rafael Alcadipani}

Pesquisador e doutorando na Manchester School of Management, UMIST. Bolsista do Governo Brasileiro (CAPES). Professor da FGV-EAESP.

E-mail: r.silveira@postgrad.umit.ac.uk 